\title{
Integrated assessment of the state of sewage mine waters based on gas-discharge radiation method
}

\author{
Natalija Glukhova ${ }^{1 *}$, Viktor Khilov ${ }^{1}$, Yuliia Kharlamova $^{1}$, and Mariia Isakova $^{1}$ \\ ${ }^{1}$ Dnipro University of Technology, 19 Yavornytskoho Ave., 49005 Dnipro, Ukraine
}

\begin{abstract}
The existing environmental problems resulting from the use and subsequent discharge of water by mining and metallurgical enterprises are analyzed. The relevance of developing methods for an integrated assessment of water properties is presented, which will allow the study of not only physical-chemical, but also the biological parameters of water. Experimental studies of water samples are conducted based on the method of gas-discharge radiation. The existing methods for extracting informative features of gas-discharge radiation images of liquid-phase objects are analyzed. Histograms of gas-discharge radiation images of various types of water were constructed and studied. The expediency of dividing images into separate fragments, characterized by common texture features, is shown. The analysis of texture features is carried out based on the use of the Fourier transform. Using the Fourier transform for the corresponding luminance vectors, the spectra have been obtained of the spatial distribution of the frequencies of brightness changes, which are used as texture features to identify the specific characteristics of the gas-discharge tracks formation. It has been determined that the developed method of water analysis allows assessing its biological properties, which is based on the values of the spatial frequency range. The advantage of the proposed method over the existing ones is the possibility of quantitative assessment in the form of numerical values of the covered range of spatial frequencies. The proposed method of studying the biological properties of water can be used as part of modern environmental monitoring systems.
\end{abstract}

\section{Introduction}

In regions with the developed mining sector, issues associated with pollution of the hydrosphere constantly arise. This is due to the fact that the technological operations while extracting various minerals are accompanied by the use and subsequent discharge of water from the quarry, mine, or drainage to the surface. These types of water are usually referred to under the common name of mine waters. The water of the mining and metallurgical complex used during the technological process is mainly discharged into natural water bodies after treatment operations, which leads to a significant deterioration of the hydrosphere.

\footnotetext{
*Corresponding author: glnavi@ukr.net
} 
Despite the fact that new methods of water treatment and reuse of the same volumes of water in the technological process are being developed, the share of reused process water remains so far insignificant. When discharging mine water into natural water bodies, it is necessary to carry out water treatment, as well as to control the properties of water used in the industry that enters natural water bodies.

During the technological processes of mining and metallurgical enterprises, there is a change in both the physical and chemical properties of water [1-6]. For example, up to 1.8 $\mathrm{m}^{3}$ of the specific volume of mine water may fall per 1 ton of coal mined. Moreover, the underground type of extraction is characterized by the predominance of groundwater coming from aquifers. As a result, mine water is usually distinguished among others by a high content of mineral salts in their composition (up to $20-30 \mathrm{~g} / \mathrm{dm}^{3}$ ). Therefore, when mine water is discharged into natural reservoirs, there is a significant increase in the salinity of natural water in the regions with large enterprises of the mining and metallurgical complex.

Chemical pollution of mine water leads to emission of various trace elements into the natural environment of natural reservoirs, as well as petroleum products and heavy metals. Thus, one of the problems arising from the discharge of mine waters is the control of their physical-chemical composition, in particular, the degree of mineralization and presence of various impurities.

The main hazardous factors of hydrosphere contamination by mine waters should also include the release of radioactive components, since they can cause significant harm to living organisms even in small concentrations [7]. Heavy metals contained in discharged process water are classified as hazardous toxic substances. Moreover, even insignificant (so-called trace) amounts of heavy metals in the composition of drinking water with a high degree of probability have a toxic effect on living organisms. The necessity to control toxic elements with modern environmental monitoring tools is regulated by the norms of the World Health Organization [ $8-10]$, as well as by a number of national standards [11, 12] and Ukrainian regulatory documents $[13,14]$.

In addition to the regulatory documents on the physical-chemical composition of water, recently in many countries standards have been introduced related to the establishment of regulations on the biological properties of water. In Ukraine, water quality control involves the study of its physical-chemical properties, organoleptic characteristics, as well as biological properties. Separately, to establish the biological properties of water, a number of standards have been developed [15 - 21].

From the point of view of studying the biological properties of water, the key link is to determine the influence of drinking water on the vital activity of organisms. Currently, the toxic factor stands out as the most dangerous, since it can have a direct negative effect on organisms. The toxic properties of drinking water lead to all sorts of diseases and lethal consequences. The toxicity indicator determines the presence of specific toxic constituents in the water. Chemical and biological methods are currently used to detect toxicity.

Chemical methods for identifying the toxic properties of water are predominantly expensive, require special sophisticated equipment and qualified maintenance personnel. Along with this, the methods currently used in Ukraine to study the biological properties of water [15-21] are mainly based on bioindication methods, the essence of which is the use of organisms (for example, fish); microorganisms and their colonies. Depending on the influence of the living conditions of organisms or microorganisms in the samples of the studied waters, a conclusion is made about the biological properties of water. Among the disadvantages of methods based on bioindication, the following can be distinguished: the complexity of transportation and storage of organisms (microorganisms used as biological indicators); subjectivity of assessments; the qualitative nature of the results, usually expressed using a rank scale in points or assessments of hazard levels: safe, dangerous, medium hazard level. 
Thus, the analysis of existing methods for assessing the physical-chemical and biological properties of sewage mine water shows the relevance and prospects of developing new approaches to the synthesis of methods for the comprehensive study of water properties that can be used as part of modern systems for organizing environmental monitoring in regions with mining enterprises of metallurgical complex.

\section{Experimental studies of water properties by gas-discharge radiation method}

To study the state of mine water, the method of gas-discharge radiation was used. When carrying out studies of liquid-phase objects on the basis of this method, there is used the possibility of recording, on the photographic material, the physical effect of gas-discharge radiation around the object arising under the influence of an external pulsed electromagnetic field. The liquid-phase object is in direct contact with the photographic material, since during the research it is placed on the surface of an X-ray or film using a special metering device.

Gas-discharge radiation around the studied sample of a liquid-phase object occurs because a high-intensity pulsed external electromagnetic field acts on a water drop. The glow around the object is characterized by a certain color scale and geometric characteristics of the manifestation of individual gas discharges, which, propagating along the surface of the photographic material, leave specific fragments of the image on it - gas-discharge tracks. In the process of experimental studies of a liquid, a pulsed electromagnetic field is formed between the electrodes, causing the discharge current to flow. The discharge current flows in a sufficiently narrow gap between the electrode and the liquid sample under study. The photometric and geometric parameters of the glow around the sample depend on the characteristics of the studied object as they are conditioned by the flow of the discharge current between the electrodes.

The result of experimental studies based on the application of the gas-discharge radiation method is a two-dimensional image that contains integral information about the state and characteristics of the investigated liquid-phase object. Currently, this method is used not only to study the properties of water [22-25], but also in the field of medical diagnostics to study the properties of biological fluids [26] and biological objects directly [27].

The properties of a water sample correlate with the photometric and geometric parameters of the recorded image, since due to the interaction of a pulsed electromagnetic field and a liquid, charged particles are emitted from the surface of the droplet, due to which the initial phase of the gas discharge is formed, and then a discharge current arises. Thus, a gas discharge between the electrodes around the surface of the test sample can be recorded on photographic material or on a digital video camera.

The currently available design options for capturing images of a gas discharge arising from an external electromagnetic field can be divided into analog and digital. Each of them is characterized by a number of advantages and disadvantages that should be taken into account in order to achieve the goals of a particular experiment. On the one hand, registration with a digital camera is a more modern option, allowing more automation of the experimental research process, avoiding operations associated with the development and further scanning of photographic material. On the other hand, modifications to the devices developed for the registration of gas-discharge radiation based on digital video cameras that have been developed so far require the supply of a large number of pulses (tens or hundreds) of electromagnetic field to the object under study, which necessarily entails the occurrence of thermal, secondary emission, as well as destructive processes [27], dynamically affecting the object in the research process. Thus, when applying a large series of pulses, the properties of the liquid sample change during the process of obtaining the resulting pattern of gas-discharge 
radiation, which ultimately represents a superposition of several stages of gas discharge formation. From the metrological point of view, this leads to the emergence of a dynamic component of the measurement error, the methods of quantitative assessment of which, and, accordingly, the correction methods are currently unknown.

With the analog method of registering images on photographic material, in most cases a single-pulse mode of exposure to the object under study is used, due to which the dynamic component of the error does not occur. An additional advantage of this modification of the method is also the possibility of placing the test sample directly on the surface of the photographic material (in contrast to a hanging drop while using the digital method), which makes it possible to record the interaction pattern of the liquid directly in the contact zone with the photographic material as well.

The method of gas-discharge radiation guarantees the study of the integral properties of water, since it allows to record the results of exposure to an electromagnetic field on the object under study. In comparison with other methods that are used to study the physicalchemical properties of water, like nuclear magnetic resonance, mass spectrometric, chromatographic, or spectroscopic one, gas-discharge radiation does not require such sophisticated measuring equipment, specially trained personnel and access to special laboratory conditions.

The disadvantage of the method of gas-discharge radiation is the need for analysis and further interpretation of the measurement results, which are presented in the form of images. Due to the limited range of measurement methods based on image registration and analysis, there are currently no universal standard approaches to interpreting the measurement results in the form of images in metrology practice, as well as methods for calculating their accuracy.

The first step in the practical application of the gas-discharge radiation method is to obtain images of gas-discharge radiation. When using the method of registering images on photographic material, the second stage is image scanning, as a result of which the radiation pattern of a liquid drop on an X-ray film is converted to a digital representation in the form of the so-called grayscale raster image. In this format, each pixel of the radiation pattern is characterized by brightness, which is encoded for shades of gray by numbers from 0 to 255 . Thus, mathematically a grayscale image is presented in the form of a matrix, the elements of which contain information about the brightness of the pixels.

Fig. 1 shows the images of gas-discharge radiation of drinking bottled water recorded on an X-ray film and converted to digital form. Drinking bottled water selected for research in its physical-chemical composition complies with Ukrainian standards.

Fig. 2 shows the images of gas-discharge radiation of water used in the technological process of a mining and metallurgical complex (mine water).

As can be seen from the comparative analysis of Figs. 1 and 2, all images of the gasdischarge glow of water droplets have some common features:

1) All images of the gas-discharge glow of liquid-phase objects have circular shape;

2) The overall pattern of the glow can be divided into zones that have a radial shape from the center of the droplet to the periphery, which is conditioned by the specifics of the gas discharge formation due to photoelectron emission of charged particles from the surface of the object under study;

3) In an analog modification of the gas-discharge radiation method, when using an X-ray film as a sensitive material, there is no variety of color palette, therefore the images used for further analysis and interpretation of the measurement results are grayscale in shades of gray;

4) All images can be divided into fragments characterized by various geometric and photometric parameters. 


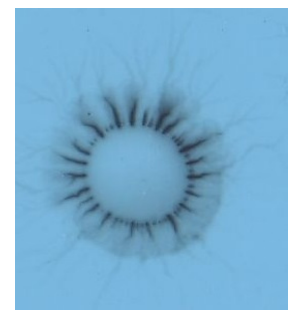

$b$

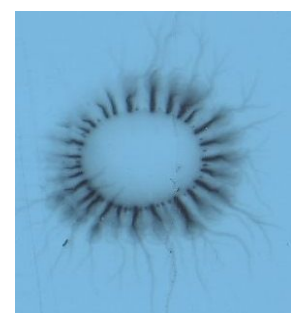

$c$

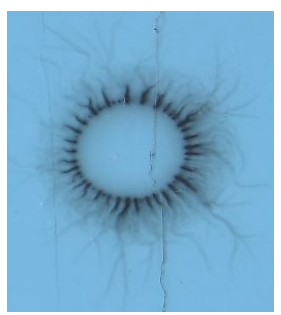

$d$

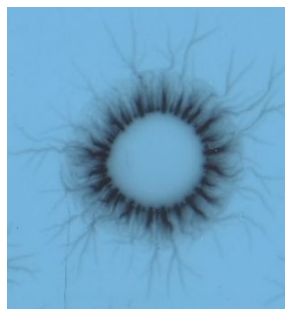

Fig. 1. Images of gas-discharge radiation of drinking bottled water (reverse image).

$a$

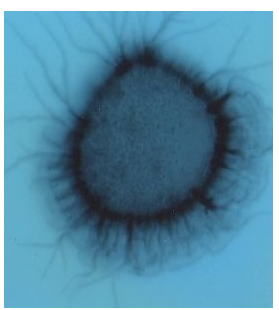

$b$

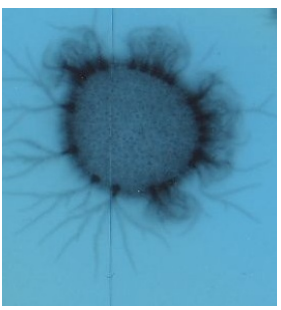

$c$

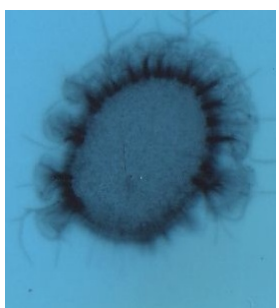

$d$

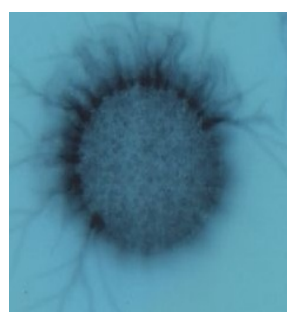

Fig. 2. Images of gas-discharge radiation of mine water (reverse image).

We consider the last item in more detail. The image of the droplet radiation always contains background - the areas of the X-ray film around the droplet that are free of recorded gas discharges. Each image has a central area of a rounded shape, which corresponds to that fragment of the film, on the surface of which a droplet is placed. As can be seen from a comparison of Figs. 1 and 2, the differences in these areas of the images can be observed even visually. For drinking bottled water, the data of the inner circle zone practically coincide in color with the background region at the edges of the images. As for the glow patterns obtained for mine water, they are, as a rule, darker and can be characterized by a greater or lesser "granularity", i.e., brightness fluctuations. For the examples of images of gas-discharge radiation shown in Fig. 2, the largest granularity is observed in images $b, d$. The third characteristic area of the image is the area of gas discharge propagation around the droplet. When the discharge current flows, separate gas discharges are formed, which are recorded on the photographic material in the form of local branched sections around the object. The distribution paths of gas discharges on a film are called gas discharge tracks or streamers. The set of streamers registered around the object is usually called a gas-discharge corona.

The preliminary analysis of the research results of the state of water can be carried out visually based on expert estimates. For example, the area of the inner circle of the object which is darker in comparison with the background of the X-ray film, with distinguishable granular inclusions indicates a large number of impurities in the composition of water. A uniformly distributed structure of the gas discharge tracks formation in the corona usually indicates satisfactory biological properties of water, in particular, its high coherence [25]. However, the visual expert assessment is approximate, being influenced by subjective factors, and cannot provide a quantitative assessment of the geometric and photometric parameters of the radiation.

To date, several methods have been proposed for quantitative analysis of images of a gas-discharge glow of water, aqueous solutions, and biological fluids. They are based on calculations of certain image characteristics associated with the properties of the investigated liquid-phase object. Moreover, most of the known approaches use generalized 
indicators that are evaluated for the image as a whole without dividing it into those fragments that were described above.

For example, in [28], two indicators were used to assess the state of water and solutions: the fractal dimension according to the Hausdorff formula, and the shape coefficient (the dissipation coefficient to assess the deviation of a quasisymmetric figure from the shape of a regular circle). These indicators were evaluated for distilled water and several standard solutions that are often used in medicine, including medical drugs (for example, $\mathrm{NaCl}$ solution; glucose and novocaine solutions with different concentrations). The author of [29] conducted research on water and aqueous solutions, during which the following parameters of the object radiation images in an electromagnetic field were assessed: the area of the glow; average radiation intensity; average image radius; standard deviation of the radius; shape factor; entropy; fractal dimension.

In contrast to the approaches developed earlier, in this paper, a variant is proposed for analyzing the image parameters of gas-discharge radiation, which is based on obtaining quantitative assessments for individual fragments of images.

\section{Results and discussion}

To analyze the geometric and photometric parameters of the images of gas-discharge radiation, we construct histograms of pixel brightness. Fig. 3 shows histograms for two samples of drinking bottled water. Fig. 4 represents histograms of mine water images.

The histogram of an image is a graph in which brightness values are indicated along the abscissa axis. In this case, for a grayscale image recorded on an X-ray film, the numerical values correspond to the luminance shades of gray halftones, which are standardly encoded for image processing software packages with numbers from 0 to 255 , with 0 corresponding to black, 255 - to white.

The ordinate axis in the image histograms is the number of pixels of the corresponding brightness. On the histograms for the registered images of gas-discharge water radiation, the brightness range from 150 to 175 corresponds to the background region, therefore, the extremum (maximum) of the graph of the histogram envelope is located in this range, since for all images the pixels corresponding to the background brightness occupy the largest area in comparison with other image fragments.

After a comparative analysis of Figs. 3 and 4, it is possible to distinguish the presence of obvious extrema in the envelope of the histogram for mine water, which are located in the brightness range from 75 to 125 . The number of pixels falling on this range at the extreme point corresponds to the bright areas that are on the image fragment corresponding to the contact zone of the liquid droplet with the photographic material. The number of pixels with such brightness exceeds 500. For images of gas-discharge radiation of drinking bottled water, these zones in terms of brightness practically coincide with those of the background, therefore there is no extremum of the histogram envelope in the brightness range $75 \div 125$.

Thus, the presence of impurities, which lead to the appearance of some radiation with subsequent fixation on the X-ray film in the contact zone of the drop with the photographic material, can be revealed during the analysis of the histogram. However, the method of gasdischarge radiation is of scientific interest not so much in the problem of detecting impurities in a liquid-phase object, as in obtaining estimates of the biological properties of water. The study of the above images of gas-discharge radiation and histograms allows to conclude that such a tool for computer analysis of images as a histogram makes it possible to perform only an integral assessment of the properties of water.

The work [24] shows the possibility of the gas-discharge radiation method for studying the biological properties of water. However, the disadvantage of this approach, which is 
based on fuzzy image clustering, is the possibility of only preliminary express assessment in the form of dividing water samples into two classes with low and high indicators of its biological properties.

$a$

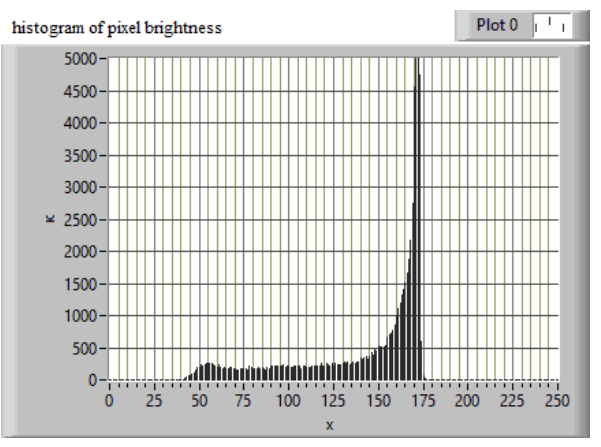

$b$

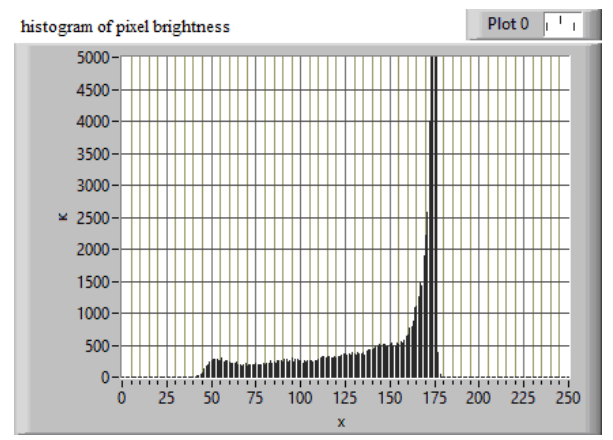

Fig. 3. Histogram plots to the images of the drinking bottled water samples.

$a$

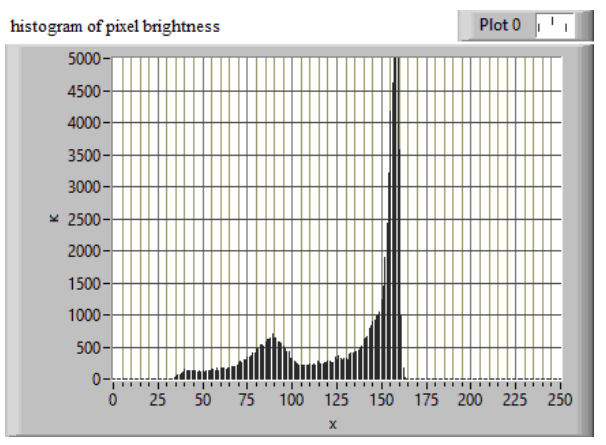

$b$

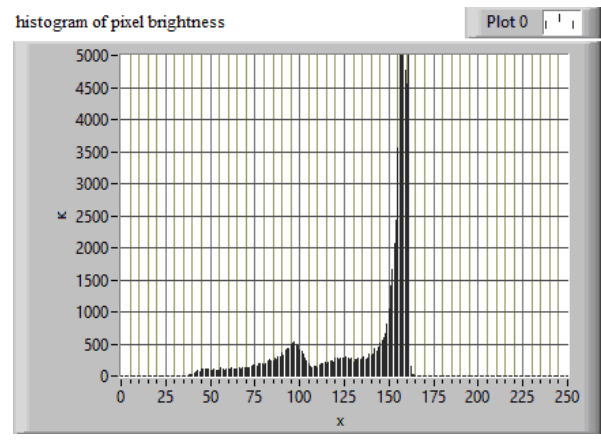

Fig. 4. Histogram plots to the images of mine water samples.

For a more detailed quantitative assessment of water properties, it is proposed to use an image analysis tool based on obtaining texture features. This approach is chosen because it provides for the possibility of analyzing separate image fragments characterized by uniformity of texture distribution within a certain area. When solving the problem of assessing the biological properties of water, it is necessary to subject the image fragments related to the zones of formation of discharge tracks to a more detailed analysis, since it is the nature of the formation of gas discharges that correlates with the composition and structure of the liquid under study.

The biological properties of water directly depend on the presence of free charge carriers in its composition, since it is their presence (or absence) that determines the key role of water (including intercellular water) in the normal course of redox reactions in living organisms.

Physical effects that occur during the formation of a gas discharge around a liquid-phase object exposed to an external electromagnetic field also depend on the presence of free charge carriers. In experimental recording of images of gas-discharge liquid radiation, the discharge current necessary for the occurrence of specific radiation can flow due to the presence of free charge carriers emitted from the surface of the liquid sample under study. 
Having compared images of gas discharge radiation for drinking bottled water (see Fig. 1) and images of mine water samples radiation (see Fig. 2), the differences can be noticed in the formation of individual discharge tracks and the so-called radiation corona as a whole. The corona, consisting of separate discharge tracks, for images of drinking water is uniformly distributed around the droplet under study. The discharge corona around the mine water samples is non-uniformly distributed around the droplet, and almost completely disappears in some sectors.

Specific differences in the formation of a corona around a droplet in images can be revealed on the basis of the analysis of the spatial organization of gas-discharge tracks, namely, their boundaries, sizes, and fragments. Due to a wide variety of applied problems related to image analysis, to date, no universal recommendations have been proposed for the formation of texture features and a reasonable choice of the window size, a synthesis theory for texture features has not been developed. Therefore, to solve these problems, it is necessary to rely on the context of applied research. In this aspect, the neighborhood of an image pixel is taken as a standard form of contextual information for analysis. The second kind of contextual information is the determination of a texture, which is a functional from a set of pixels of a part of an image in a window selected for analysis. Thus, at the moment, the nature of the procedures for the formation of texture features is selected depending on a specific applied research problem, and their effectiveness is determined empirically.

Since digitally the image is presented in the form of a matrix of values for pixel brightness, the texture is actually a matrix being a fragment of the spatial and photometric parameters of the image area. However, it should be understood that not any arbitrarily selected area of the image can be considered as a texture, but only the one that is characterized by homogeneous statistical properties (which can be determined, for example, by analyzing the image histogram). As a result, the texture can be described on the basis of some general properties, which are further used for the classification procedure, in this case, to classify types of water according to its biological properties.

When analyzing images of gas-discharge radiation, there is a quite obvious problem of choosing the size of a sliding window that covers an area of an image with a uniform texture. The size of the window should be such that a fragment with a fixed set of gasdischarge tracks fits into it. This window size allows analyzing features that are associated with measurements of the spatial frequencies of changes in brightness in the image.

To analyze texture features that are based on measuring the spatial frequency, the Fourier transform for an image is used:

$$
F(v, w)=\int_{-\infty}^{+\infty} f(x, y) e^{-2 \pi i(v x+w y)} d x d y
$$

For a digital image

$$
f(x, y)=\left[\begin{array}{cccc}
f(0,0) & f(0,1) & \ldots & f(0, N-1) \\
f(1,0) & f(1,1) & \ldots & f(1, N-1) \\
\ldots & \ldots & \ldots & \ldots \\
f(M-1,0) & f(M-1,1) & \ldots & f(M-1, N-1)
\end{array}\right],
$$

is an image matrix that contains the values of the pixel brightness.

Since the digital image is discrete, it is necessary to replace the continuous Fourier transform (1) with a discrete one:

$$
F_{d}(v, w)=\frac{1}{n^{2}} \int_{j=0}^{n-1} \int_{m=0}^{n-1} f(j, m) e^{-2 \pi i(j v+m w)}, 0 \leq(v, w) \leq n-1 .
$$


To simplify the computational procedures and the possibility of transition to the onedimensional Fourier transform, the window matrix was replaced by a vector, which consists of a sequence of rows of the original matrix.

In order to identify specific features of textures in the image of gas-discharge radiation areas that contain gas-discharge tracks, three groups of water were analyzed: waste water from industrial enterprises, water supply from technologically loaded areas with a high concentration of enterprises, and additionally purified drinking bottled water. For the analysis of texture features, the vectors of the glow brightness for texture fragments were generated by software. For these three groups of water studied by the method of gasdischarge radiation, the graphs of the change in brightness depending on the coordinate (i.e., a graphical representation of the brightness vector) are shown in Fig. 5, $a-c$.

$a$
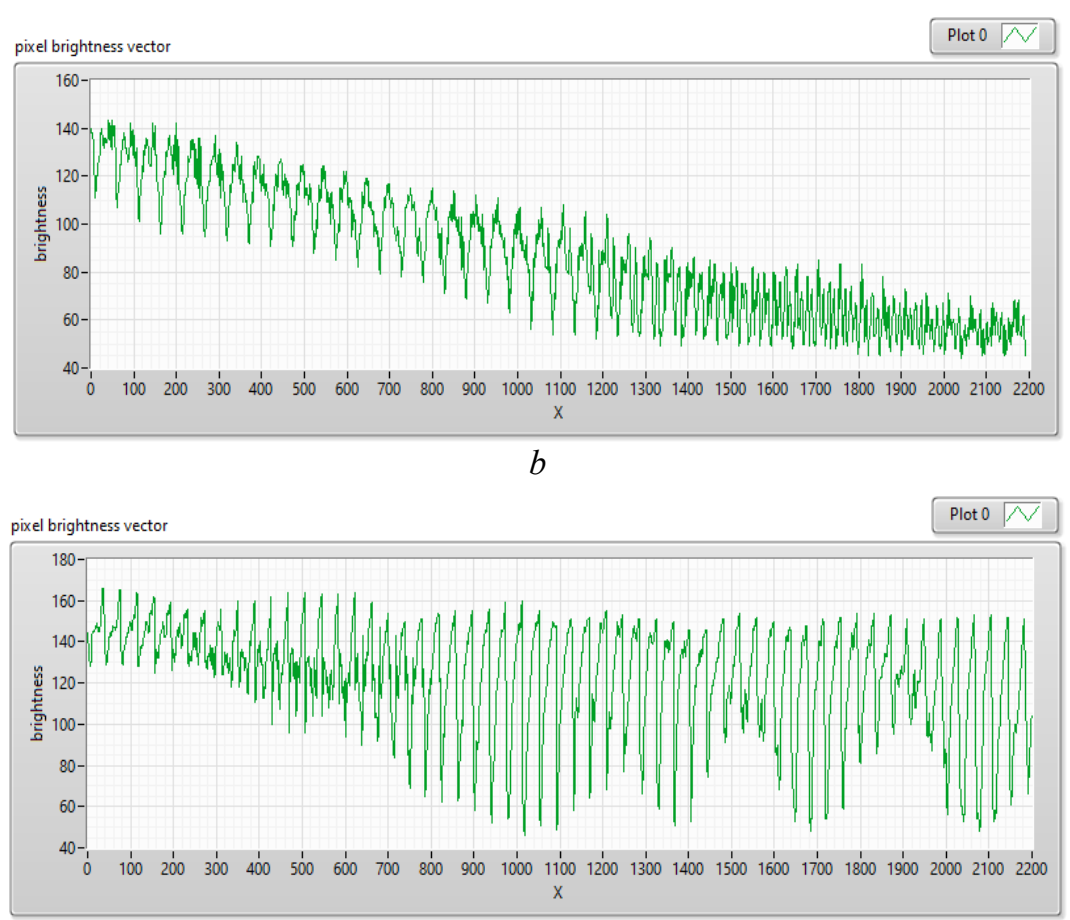

$c$

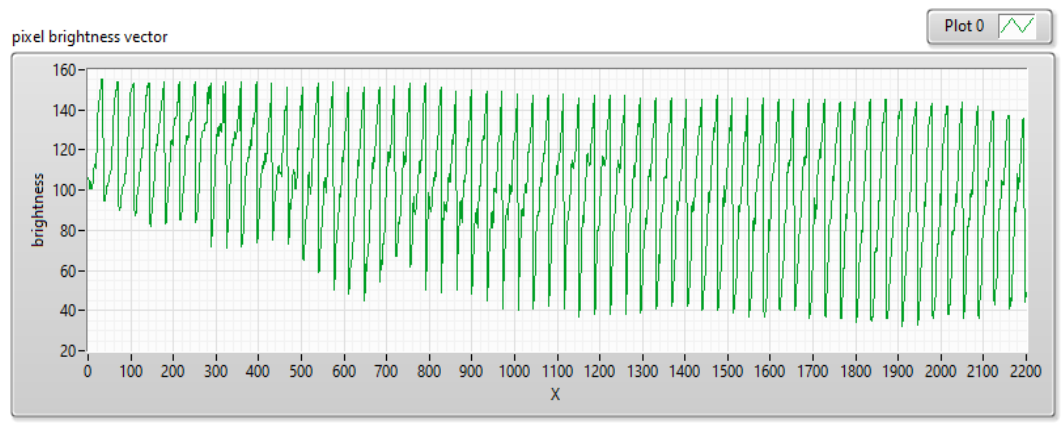

Fig. 5. Curves of dependences of changes in brightness on the coordinate for three types of water: $a$-waste water from industrial enterprises; $b$ - mains water; $c$-additionally purified drinking bottled water. 
For the corresponding brightness vectors, using the Fourier transform, spectra of the spatial distribution of the brightness change frequencies were obtained, which are used as textural features to reveal the specific characteristics of the formation of gas-discharge tracks for different water samples (Fig. 6).

$a$

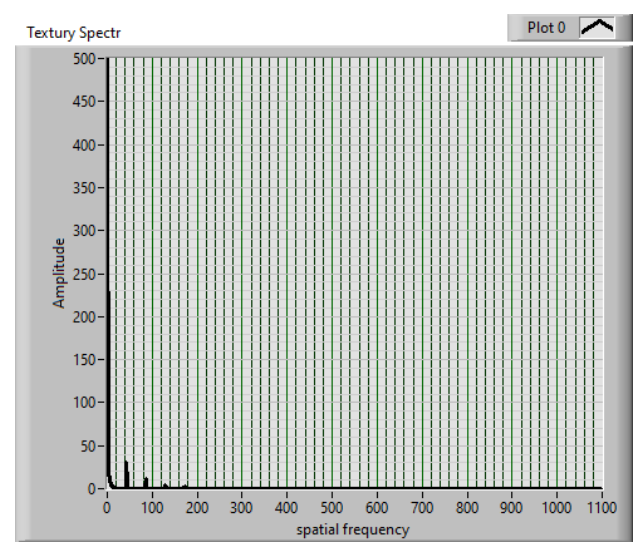

$c$

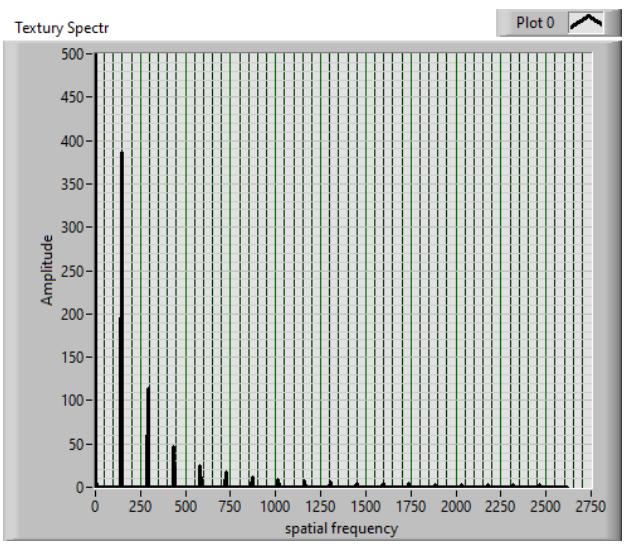

$b$

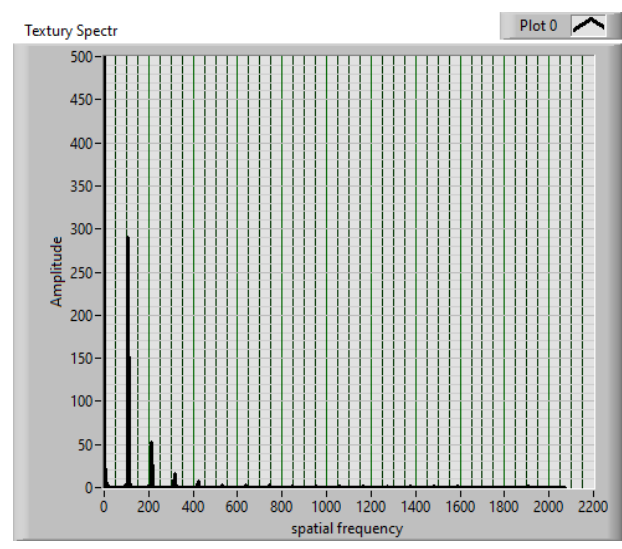

Fig. 6. Spectrum plots for the spatial frequency of three types of water: $a$-waste water from industrial enterprises; $b$-mains water; $c$ - additionally purified drinking bottled water.

As can be seen from the analysis of Fig. 6, for images of waste water, the spectrum is characterized by the least variety of spatial frequencies (from 0 to 200), the amplitudes are located at low frequencies. The amplitude spectrum of spatial frequencies for additionally purified bottled water is the broadest of all the samples presented, the amplitudes in it are observed in the range of spatial frequencies from 0 to 2500 . A sample of mains water is characterized by average values of spectral features: the amplitudes also decrease from lower frequencies to higher frequencies and cover the range of spatial frequencies from 0 to 800 .

\section{Direction of further research}

Since at present, as a result of technogenic pollution, there is a significant deterioration of the ecological situation in many regions, in particular, the pollution of the hydrosphere with wastes from industrial enterprises, among the tasks of further water quality studies, the following can be distinguished: 
1. The necessity of assessment of not only certain physical-chemical parameters of water, but a comprehensive assessment of water quality, which should include the assessment of its biological properties.

2. At present, in Ukraine, in the overwhelming majority of cases, methods based on the use of biological tests are used to study the biological properties of water. They are characterized by a number of disadvantages: labor intensity; large time costs; the need to attract specially trained personnel; requirements for ensuring certain storage conditions for biotests, which complicates their transportation; obtaining a result in a qualitative form according to a rank scale. Therefore, one of the necessary directions is the development of methods for determining the biological properties of water, which will allow evaluating the results in quantitative form as well as increasing the research reliability.

3. Development of such methods for assessing the biological properties of water, which will allow research within a short period of time and can be used in modern systems of environmental monitoring in the conditions of the mining and metallurgical complex.

4. A further development of the methodology proposed in this work for assessing the biological properties of water can be the accumulation of statistical material in the study of various water samples. This will make it possible in the future to develop more precise quantitative criteria for assessing the biological properties of water associated with the presence of free charge carriers in its composition, and, consequently, the ability of water to ensure the normal course of redox reactions in living organisms.

\section{Conclusions}

For the analysis of the biological properties of water, an analysis method based on obtaining textural features is proposed. The specific differences in the pattern of gasdischarge tracks formation under the influence of an external electromagnetic field are manifested in certain areas of the image, thus the developed approach provides for the use of a window covering the fragments containing the radiation corona around the liquidphase object under study. For the selected fragments, the values of the brightness amplitudes, formed for certain spatial frequencies are used as texture features based on the application of the Fourier transform to the brightness vectors.

The results obtained from the application of the developed approach have demonstrated its effectiveness for studying the biological properties of different types of water. For polluted waste water, a narrowing of the spectrum of spatial frequencies is characteristic in comparison with samples of additionally purified drinking water.

The advantage of this method for analyzing the biological properties of water is the possibility of a qualitative assessment, which is based on the values of the spatial frequency range: the narrower it is, the lower the bioavailability of water. In addition to a qualitative assessment, a quantitative assessment in the form of numerical values of the covered range of spatial frequencies can also be used.

The authors express their gratitude to all who contributed to the realization of this project. This project would not have been possible without the support of the staff of the Department of Geodynamic Systems and Vibration Technologies of the Institute of Geotechnical Mechanics named after N.S. Polyakov National Academy of Sciences of Ukraine.

\section{References}

1. Matlak, E.S., \& Maleev, V.B. (1991). Snizhenie zagryaznennosti shakhtnykh vod v podzemnykh usloviyakh. Kyiv: Tekhnika, 134. 
2. Parakhonskiy, Z.V. (1992). Okhrana vodnykh resursov na shakhtakh i razrezakh. Moskva: Nedra, 190.

3. Khokhryakov, A.V. (2005). Kolichestvennaya otsenka vklada vzryvnykh rabot v zagryaznenie drenazhnykh vod kar'erov soedineniyami azota. Izvestiya Vuzov. Gornyy Zhurnal, (6), 29-31.

4. Dolina, L.F. (2000). Stochnye vody predpriyatiy gornoy promyshlennosti i metody ikh ochistki. Dnipropetrovsk: Molodezhnaya ekologicheskaya liga Pridneprov'ya, 43.

5. Sheynkman, L.E., \& Dergunov, D.V. (2011). Zashchita poverkhnostnykh i podzemnykh vod ot zagryazneniya fenolami pri podzemnoy dobyche uglya. In IV Mezhdunarodnaya NauchnoPrakticheskaya Konferentsiya "Tekhnicheskie nauki - ot teorii k praktike" (pp. 56-61) Novosibirsk, Russia: SibAK.

6. Udalov, I.V. (2005). Osobennosti tekhnogennogo zagryazneniya podzemnykh vod (na primere Svetlichanskogo vodozabora Luganskoy oblasti). Vestnik Kha'kovskogo Politekhnicheskogo Instituta, (27), 115-121.

7. Surovtsev, I.V., Babak, O.V., Tatarinov, O.Ye., \& Surovtseva, T.V. (2011). Aparatno-prohramnyi kompleks "Analizator IKhP" dlia vymiriuvannia masovoi kontsentratsii toksychnykh elementiv. Nauka ta Innovatsii, 7(3), 45-46.

8. Guidelines for Drinking-Water Quality. (1993). Geneva, Switzerland: World Health Organization, 188.

9. Interim Canadian Environmental Quality Criteria for Contaminated Sites (1991). Winnipeg, Manitoba, 20. Retrieved from https://www.ccme.ca/files/Resources/csm/pn_1007_e.pdf

10. The Draft ECE Classification of Ecologycal Freshwater Quality, CES/668. (1990). Geneva, Switzerland, 25.

11. Fomin, G.S. (1995). Voda. Kontrol' khimicheskoy, bakterial'noy i radiatsionnoy bezopasnosti po mezhdunarodnym standartam. Entsiklopedicheskiy spravochnik. Moskva: Protektor, 624.

12. Normes francaises pour l'eau potable: Decret № 91-257 du 7-3-1991 modifiant le decret № 89-3 du 3-1-1989.

13. Guseva, T.V., Molchanova, Ya.P., \& Zaika, Ye.A. (2000). Gidrokhimicheskie pokazateli sostoyaniya okruzhayushchey sredy. Moskva, Russia: Ekolayn, 265.

14. Tyazhelye metally $v$ pochvakh. Predel'no dopustimye kontsentratsii (PDK) khimicheskikh veshchestv v pochvakh. Retrieved from http://www.gidrogel.ru/ecol/hv met.htm

15. DSTU 4174:2003. (2003). Yakist vody. Vyznachannia khronichnoi toksychnosti khimichnykh rechovyn ta vody na Daphnia magna Straus ta Ceriodaphnia affinis Lilljeborg (ISO 10706:2000, MOD) (Cladocera, Crustacea). Kharkiv: Ukrainskyi naukovo-doslidnyi instytut ekolohichnykh problem.

16. DSTU 7387:2013. (2013). Yakist vody. Metod vyznachennia tsyto- ta henotoksychnosti vody $i$ vodnykh rozchyniv na klitynakh krovi prisnovodnoi ryby Danio rerio (Brachydanio rerio Hamilton-Buchanan). Kyiv: Instytut koloidnoi khimii ta khimii vody im. A.V. Dumanskoho NAN Ukrainy

17. DSTU EN 26461-1:2002. (2002). Yakist vody. Vyiavliannia $i$ pidrakhovuvannia spor sulfitoredukuvalnykh anaerobiv (klostrydium). Chastyna 1. Metod zbahachennia $v$ ridkomu seredovyshchi (EN 26461-1:1993, IDT). Kyiv: Instytut vodnykh problem i melioratsii Natsionalnoi akademii ahrarnykh nauk Ukrainy.

18. DSTU EN 26461-2:2004. (2004). Yakist vody. Vyiavlennia $i$ pidrakhovuvannia spor sulfitoredukuvalnykh anaerobiv (klostrydium). Chastyna 2. Metod membrannoho filtruvannia. Kyiv: Instytut vodnykh problem i melioratsii Natsionalnoi akademii ahrarnykh nauk Ukrainy.

19. DSTU ISO 6222-2002. (2002). Yakist vody. Pidrakhovuvannia mikroorhanizmiv, shcho utvoriuiut kolonii. Pidrakhovuvannia kolonii inokuliatsiieiu $v$ zhyvylne aharove seredovyshche (ISO 6222:1999, IDT). Kyiv: Instytut vodnykh problem i melioratsii Natsionalnoi akademii ahrarnykh nauk Ukrainy.

20. DSTU ISO 10712:2003. (2003). Yakist vody. Vyprobovuvannia na pryhnichennia rostu PSEUDOMONAS PUTIDA (vyprobovuvannia na pryhnichennia rozmnozhuvannia klityn 
PSEUDOMONAS) (ISO 10712:1995, IDT). Kharkiv: Ukrainskyi naukovo-doslidnyi instytut ekolohichnykh problem.

21. DSNU ISO 13829:2003. (2003). Yakist vody. Vyznachannia henotoksychnosti vody $i$ stichnoi vody z vykorystovuvanniam UMU-testu (ISO 13829:2000, IDT). Kharkiv: Ukrainskyi naukovodoslidnyi instytut ekolohichnykh problem.

22. Abella, A., Amorós, A., González, M., del Corral, A., \& Peña, J. (2017). Analysis with Gas Discharge Visualization of the Possible Effects on Water in Different Containers. Water, (3), 165171. https://doi.org/10.14294/WATER.2017.3

23. Pesotskaya, L.A., Glukhova, N.V., Lapytskiy, V.N. (2013). Analiz izobrazheniy kirlianovskogo svecheniya kapel' vody. Naukovyy Visnyk Natsionalnoho Hirnychoho Universytetu, (1), 91-96.

24. Glukhova, N.V. (2014). Development of express-evaluation method of water biological properties. Eastern-European Journal of Enterprise Technologies, 6(5(72)), 18-25. https://doi.org/10.15587/1729-4061.2014.31546

25. Glukhova, N.V. (2020). Method for Determining the Measurement Uncertainty of the Detailing Coefficients of the Wavelet Transform of Image Brightness Profiles. Measurement Techniques, 63(3), 177-183. https://doi.org/10.1007/s11018-020-01769-1

26. Glukhova, N.V. (2015). Cluster Analysis for Measurements of Gas-Discharge Emission Parameters for Blood Samples. Measurement Techniques, (58), 1066-1070. https://doi.org/10.1007/s11018-015-0843-7

27. Korotkov, K.G. (2017). Metod GRV bioelektrografii na sovremennom etape. Sankt-Peterburg, Russia: SPbU ITMO, 135.

28. Kolomiiets, R.O. (2011). Biotekhnichna systema na osnovi efektu Kirlian dlia analizu ridynnofaznykh obiektiv. PhD Thesis. Vinnytsia, Ukraine: VNTU.

29. Kryzhanovskiy, E.V. (2003). Metod kontrolya zhidkofaznykh ob'ektov na osnove gazorazryadnoy vizualizatsii. PhD Thesis. Sankt-Peterburg, Russia: SPbGU ITMO. 